\title{
Use of spent coffee grounds as food ingredient in bakery products
}

\section{Nuria Martinez-Saeza, Alba Tamargo García ${ }^{a}$, Inés Domínguez Péreza, Miguel Rebollo-Hernanza, Marta Mesías ${ }^{b}$, Francisco J. Moralesb, María A. Martín-Cabrejasa, Maria Dolores del Castilloa,*}

${ }^{a}$ Institute of Food Science Research (CIAL, UAM-CSIC), 28049 Madrid, Spain

${ }^{\mathrm{b}}$ Institute of Food Science, Technology and Nutrition, ICTAN-CSIC, Madrid 28040, Spain

\begin{abstract}
The present research aimed to evaluate the use of spent coffee grounds (SCG) from instant coffee as a food ingredient and its application in bakery products. Data on physicochemical characterization, thermal stability and food safety of SCG were acquired. Evaluation of feasibility as dietary fibre was also determined. Results showed SCG are natural source of antioxidant insoluble fibre, essential amino acids, low glycaemic sugars, resistant to thermal food processing and digestion process, and totally safe. In the present work, SCG were incorporated in biscuit formulations for the first time. Low-calorie sweeteners and oligofructose were also included in the food formulations. Nutritional quality, chemical (acrylamide, hydroxymethylfurfural and advanced glycation end products) and microbiological safety and sensory tests of the biscuits were carried out. Innovative biscuits were obtained according to consumers' preferences with high nutritional and sensorial quality and potential to reduce the risk of chronic diseases such as obesity and diabetes.
\end{abstract}

KEYWORDS: Spent coffee grounds, antioxidant dietary fibre, food grade ingredient, bakery products

\section{INTRODUCTION}

Spent coffee grounds (SCG) are the most abundant coffee byproduct (45\%) generated in coffee beverage preparation and instant coffee manufacturing (Murthy \& Naidu, 2012b). About $2 \mathrm{~kg}$ of wet SCG are obtained from each $\mathrm{kg}$ of instant coffee produced, with an annual generation of around 6 million tons worldwide (Mussatto, Machado, Martins, \& Teixeira, 20II). To date, several applications have been described for SCG, mainly as biofuels, composts, animal feed, biosorbents and enzymes. Recently, an increase in food and health application is occurring (Del Castillo, Fernandez-Gomez, Martinez-Saez, Iriondo, \& Mesa, in press). Previous studies performed by our group indicated the importance of SCG as source of antioxidant dietary fibre (Del Castillo, Martinez-Saez, \& Ullate, 20I4).

Consumers are concerned about caloric content and glycaemic index $(\mathrm{Gl})$ of the food as well as balanced nutrition comprising dietary fibre content. The benefits of low $\mathrm{Gl}$ diets extend beyond weight loss and have favourable effects on obesity-related diseases such as type 2 diabetes (Esfahani, Wong, Mirrahimi, Villa, \& Kendall, 20l I). Food industry needs to fulfil the increasing consumer's demand of healthier and tastier foods. The search for healthier and tasty food as for instance bakery products is a necessity in our population. Maillard reaction is the main chemical event occurring during coffee roasting and baking. The reaction affects nutritional quality, safety and sensory value. Maillard reaction products present health promoting (melanoidins) and potential harmful effects (acrylamide, furans and advanced glycation end products) (Tamanna \& Mahmood, 2015). The present work aims to evaluate the use of SCG as food ingredient in innovative bakery products with high nutritional and sensorial quality and potential to reduce the risk of chronic diseases such as obesity and diabetes.

\section{MATERIALS AND METHODS}

\section{Reagents}


Bradford reagent was provided by Bio-Rad Laboratories S.A; $\alpha$-amylase from human saliva (type IX-A), porcine pepsin from gastric mucosa (3.200-4.500 U/mg protein), pancreatin from porcine pancreas, porcine bile extract, bovine serum albumin (BSA), chlorogenic acid (CGA) (3-CGA), 2,20-azino-bis (3ethylbenzothiazoline-6-sulphonic acid (ABTS)), Folin-Ciocalteu reagent, Na-Acetyl-L-lysine, orthophthalaldehyde (OPA), I-deoxy-I-morpholinofructose (DMF), nitroblue tetrazolium (NBT), butylated hydroxytoluene and proteinase $k$ from Pichia pastoris were from Sigma-Aldrich (St. Louis, MO, USA). Bradford reagent was provided by Bio-Rad Laboratories S.A, glucose kit from Spinreact (Gerona, Spain), total dietary fibre kit from Megazyme (International Ireland Ltd) and advanced glycation end products assay kit from Lamider ${ }^{\circledR}$ (México, D.F., México). Buffered peptone water (BPW) from Biocult, plate count agar (PCA) medium from BD DiftcoTM, brain heart infusion (BHI) agar from BD Bacto ${ }^{\mathrm{TM}}$ (New jersey, USA) and sabouraud dextrose agar (SDA) with chloramphenicol from CONDA (Pronadisa). Water was purified using Milli-Q and Elix system. All other chemicals and reagents were of analytical grade.

\section{Apparatus}

BioTek powerWaveTM XS (BioTek Instruments, U.S.A) and FP-6200 (JASCO, Easton, U.S.A) microplate spectrometers, Agilent GI6000A capillary electrophoresis (Agilent, Madrid, Spain), convection oven (Romag S.A, Barcelona, Spain), UN 500 universal oven (Memmert, Germany), Telstar Lyobeta-15 lyophilizer (Telstar, Spain), CertoCLAV A-4050 autoclave (CertoCLAV, Austria), AW Sprint TH-500 water activity system (Novasina, Switzerland), Shimadzu HPLC system (Kyoto, Japan), Agilent 1200 liquid chromatograph coupled to an Agilent Triple Quadrupole MS detector (Agilent Technologies, Palo Alto, CA, USA) and Biochrom 30 Amino Acid Analyzer (Cambridge, UK) were used for analysis. Stomacher ${ }^{\circledR} 400$ Circulator (Seward, U.K.), horizontal laminar flow bench Mini-H (Telstar, Spain), Nüve ENI 20 incubator (Nüve, Turkey) and SANYO Mir 154 incubator (SANYO Electric Biomedical Co., Ltd. UK) were also needed for microbiological studies.

\section{SCG samples}

Raw coffee by-product: SCG from industrial soluble coffee production of the Robusta specie were provided by Prosol S.A (Spain) and stored under $-20^{\circ} \mathrm{C}$ until preparation of the biscuits and microbiological analysis. Information regarding to the thermal stability of SCG dietary fibre was obtained by treating the sample under those conditions used for the baking of biscuits $\left(185^{\circ} \mathrm{C}, 16 \mathrm{~min}\right)$.

Stabilized SCG: Different drying conditions were applied on raw SCG $\left(40^{\circ} \mathrm{C}, 70^{\circ} \mathrm{C}\right.$ and $\left.100^{\circ} \mathrm{C}\right)$ until constant weight was achieved. Samples were stored at room temperature in dry and fresh place for $24 \mathrm{~h}$, until analyses of their physical properties (moisture loss, moisture content and water activity) and microbiological quality. Energy consumption (kW.h) was calculated for each drying condition by correlation of consumption and operating temperature. Calculation was performed in order to validate the feasibility of the method for its industrial use.

Freeze-dried SCG: The raw material was lyophilized and stored in dry and cool place until analysis of its physico-chemical properties (moisture, water activity, ashes, dietary fibre, proteins, amino acid composition, fat, carbohydrates and antioxidant capacity) and safety by means of the quantification of food processing contaminants (acrylamide and hydroxymethylfurfural).

In vitro oral gastrointestinal digestion was carried out to evaluate the resistance of SCG to digestion process. The freeze-dried SCG were digested as described by Hollebeeck, Borlon, Schneider, Larondelle, and Rogez (20I3), with slight modifications. All three stages (salivary, gastric and duodenal) were performed in the same flask covered with aluminium foil. Approximately I.2 g of SGC were weighed. Conditions were set up 
as follows: salivary step ( $\mathrm{pH} 6.9,10 \mathrm{ml}, 5 \mathrm{~min}, 3.9 \cup \alpha$-amylase $/ \mathrm{ml}$, aerobic), gastric step (pH 2, $13 \mathrm{ml}, 90$ $\mathrm{min}, 71.2 \mathrm{U}$ pepsin/ml, aerobic), and abiotic duodenal step $(\mathrm{pH} 7,16 \mathrm{ml}, 150 \mathrm{~min}, 9.2 \mathrm{mg}$ pancreatin and 55.2 $\mathrm{mg}$ bile extract $/ \mathrm{ml}$, aerobic). The obtained digests were centrifuged and separated in two fractions, supernatant and precipitate. The content of dietary fibre was determined in the precipitate (nondigestible fraction also called colonic fraction). Finally, the soluble fraction was treated to mimic human intestinal reabsorption of bile salts. Cholestyramine resin $(10 \% \mathrm{w} / \mathrm{v})$ previously activated was used as bile acids precipitating agent (Edwards \& Slater, 2009) for I h at room temperature by mixing with magnetic stirrer. Cholestyramine was removed by centrifugation and gravimetric filtration. The antioxidant capacity and total phenol content of supernatants free of bile salts containing the bioaccesible compounds in the intestinal lumen were analysed. A food control composed by starch, bovine serum albumin and oil was included. Digestion process was carried out in duplicate and the analysis of the samples in triplicate.

Aqueous SCG extracts: An extractable fraction from freeze-dried SCG was obtained with hot water (50 $\mathrm{mg} / \mathrm{ml}$ ) at $100^{\circ} \mathrm{C}$ for $10 \mathrm{~min}$ as described in the patent WO 2013/004873. Extracts were stored at $-20^{\circ} \mathrm{C}$ until use. Further chemical analyses (free glucose, antioxidant capacity, total phenolic content, CGA and caffeine) were carried out to gain insight on soluble compounds present in SCG. The analysis of the fraction aimed to assess the interest for extracting other compounds beside dietary fibre from the brewing coffee by-products and to reinforce its value as natural abundant source of antioxidant dietary fibre.

\section{Biscuits samples}

Food ingredients

For the biscuits formulations, all basic ingredients were purchased at specialized and certified food markets. Food grade soy lecithin was provided by Manuel Riesgo S.A. (Spain) and maltitol was supplied by a national food company. The commercial stevia sweetener powder which contained $3 \%$ steviol glycosides, was supplied by Gerblé (Spain) and oligofructose powder (ORAFTI $\left.{ }^{\circledR} \mathrm{P} 95\right)$ by Beneo-Orafti.

\section{Biscuits formulations}

A total of 6 innovative free-sugar biscuits (BI, B2, B3, B4, B5, B6) were formulated as indicated in Table I. Biscuits were prepared using as basic ingredients wheat flour and sunflower oil. Egg was not incorporated and sucrose was replaced by stevia and/or maltitol as natural hypocaloric sweeteners. SCG were included as antioxidant insoluble dietary fibre. The amount of SCG added to the biscuits ranged 3.5-4.4\%, in order to achieve the nutritional claims "source of fibre" (P3 g fibre/l00 g biscuit) and "high fibre content" (P6 g fibre/l00 g biscuit). Oligofructose was included as enhancer of glucose tolerance (soluble fibre), gut microbiota (prebiotic), texture and taste. The preparation of the doughs follows the same procedure performed by Garcia-Serna, Martinez-Saez, Mesias, Morales, and Del Castillo (2014). The biscuits were baked at $185^{\circ} \mathrm{C}$ for $16 \mathrm{~min}$ in an air recirculation oven.

Three commercial biscuits with high consumer adhesion were purchased and used as references in the present research. The biscuit containing maltitol and isomaltitol as sweeteners and $3.6 \%$ dietary fibre was named as $\mathrm{Cl}$. C2 biscuit was based on maltitol as sweetener and $8.3 \%$ dietary fibre. $\mathrm{Cl}$ and $\mathrm{C} 2$ were used as references in the sensorial analysis since those contain similar composition to that of the innovative foods. The commercial biscuit (CSB) containing sucrose as sweetener was used as a control of the average formation of potential harmful compounds during food processing (see ingredients and nutritional composition provided in the Supplementary material section of the article). 
Proteins, soluble free amino groups, fructosamine, advanced glycation end products in the new food (B2) and commercial sucrose biscuit (CSB) were evaluated. Microbiological quality and food processing contaminants were also analysed on B2 biscuit and a control biscuit elaborated using the same ingredients and recipe employed for preparing B2 without addition of SCG. A sensorial test was carried out to evaluate the sensorial quality of all the innovative biscuits (BI-B6).

B2 was selected as new healthier food due to its high nutritional and sensorial quality and safety. A limited formation of potential harmful Maillard reaction products (MRPs) was expected by replacing sugar sweetener by stevia. This sweetener presents benefits for diabetes.

\section{Physicochemical analyses}

Moisture

Moisture content was determined by gravimetric method as described in AOAC-925.10, at $105^{\circ} \mathrm{C}$ until constant weight. Results were expressed as\%.

Water activity (aw)

It was measured in a water activity system at $25^{\circ} \mathrm{C}$. The calibration was carried out as indicated by the manufacturer. A humidity standard, SALT-T75, was used for the basic calibration. This standard was inserted in the measuring chamber and the instrument carried out the calibration whilst at the same time determining the heating compensation value.

Ashes

The amount of ashes was quantified by the AOAC- 923.03 based on the complete incineration of organic matter at $550^{\circ} \mathrm{C}$. Results were expressed as $\%$.

Dietary fibre

Insoluble (IDF), soluble (SDF) and total (TDF) dietary fibre were determined by using enzymatic-gravimetric assay based on the AOAC-99I.43 and AACC-32.07.01 method. Results were expressed as \%.

Total protein

Content of proteins was determined by Kjeldahl mineralization followed by a colorimetric analysis of nitrogen for quantification (AOAC-32.1.22, 920.87). $\mathrm{NH}_{4} \mathrm{Cl}$ was used for standard calibration curve. A conversion factor (6.25) was used to calculate proteins content. Results were expressed as \% dry matter (d.m.).

Soluble proteins

Bio-Rad Protein Assay (Bio-Rad Laboratories) based on the method of Bradford was used in micro-method format to determine protein concentration. Briefly, a solution of Bradford reagent ( $1: 4$, reagent:milli-Q water) was prepared and filtered using Whatman 4 filter. Ten $\mu \mathrm{l}$ of sample and $200 \mu \mathrm{l}$ of Bradford solution were placed in a multi-well microplate. Samples were incubated for 5 min at room temperature, and the absorbance was measured at $595 \mathrm{~nm}$. Sample blank and reagent blank were also analysed. A calibration curve was constructed using BSA $(0.05-0.5 \mathrm{mg} / \mathrm{ml})$. All measurements were performed in triplicate. Results were expressed as $\mathrm{mg} \mathrm{BSA} / \mathrm{g}$.

Free amino groups 
An OPA assay was employed to determine the content of free amino groups (Michalska, Amigo-Benavent, Zielinski, \& del Castillo, 2008). Quantitative analysis was performed by the external standard method, using a calibration curve of Na-acetyl-L-lysine ( $10-250 \mu \mathrm{mol} / \mathrm{l})$. The results were expressed as $\mathrm{mg}$ Lys eq./g biscuit and $\mathrm{mg}$ Lys eq./g protein.

Amino acids composition

Amino acid analysis was performed according to AOAC-994.12 method, which is based on acid hydrolysis of sample followed by HPLC with post column derivatization using ninhydrin. Analysis in triplicate was performed and results were expressed as \% protein.

\section{Fructosamine}

Prior to the analysis the biscuits were treated with PBS $(\mathrm{I} \mathrm{g}$ sample in $10 \mathrm{ml})$ containing BHT $(0.2 \mathrm{mM})$ for $48 \mathrm{~h}$ at $4^{\circ} \mathrm{C}$. Later, enzymatic hydrolysis was performed by incubating sample overnight with proteinase $\mathrm{k}$ $(0.2 \% \mathrm{p} / \mathrm{p})$ at $37^{\circ} \mathrm{C}$. The reaction was stopped at $65^{\circ} \mathrm{C}$ for $\mathrm{I} \mathrm{h}$ and centrifuged $(1000 \mathrm{rpm}, 10 \mathrm{~min})$ to keep supernatant for further analysis.

NBT assay was performed to determine fructosamine following the micromethod of Vlassopoulos, Lean, and Combet (20l3). Briefly, samples $(25 \mu \mathrm{l})$ were added to sodium carbonate buffer $(100 \mu \mathrm{l}, 100 \mathrm{mM}, \mathrm{pH} 10.8)$ with nitroblue tetrazolium $(0.25 \mathrm{mM})$. Microplates were incubated for $20 \mathrm{~min}$ at $37^{\circ} \mathrm{C}$ and measured spectrophotometrically against control at $530 \mathrm{~nm}$. The fructosamine analogue DMF (I-deoxy-Imorpholinofructose) was used as standard. All measurements were performed in triplicate and expressed as $\mu \mathrm{g}$ DMF eq.// $00 \mathrm{~g}$ biscuit and $\mu \mathrm{g} \mathrm{DMF}$ eq./mg protein.

Fat

Total fat content was quantified by Soxhlet extraction with petroleum ether (AOAC 945.16) applying previously an acid hydrolysis (AOAC 922.06). Results were expressed as \% d.m.

\section{Total carbohydrates}

Carbohydrates were calculated by difference following this formula:

100 - (weight in grams [protein + fat + water + ash + fibre] $)$

Results were expressed as \% d.m.

Free glucose

The procedure for determining the amount of glucose was performed by using an enzymatic kit as per the manufacturer's instructions. Analysis was carried out in triplicate. Results were expressed as mg/l00 g SCG.

\section{Caffeine and CGA}

The procedure was performed according to Del Castillo, Ames, and Gordon (2002). Separation was carried out in a capillary electrophoresis system with an ultraviolet-visible detection. Calibration curves of caffeine $(0.25-5.15 \mathrm{mmol} / \mathrm{l})$ and CGA $(0.15-2.5 \mathrm{mmol} / \mathrm{l})$ were constructed. The analyses were performed in triplicate. Results were expressed as\% 3-CGA (w/w) and \% caffeine $(w / w)$.

\section{Total phenolic content}

Total phenolic content (TPC) was determined by the Folin-Ciocalteu method as described by Contini, Baccelloni, Massantini, and Anelli (2008) adapted to a micro-method format. CGA calibration curve (0.I-0.8 $\mathrm{mg} / \mathrm{ml}$ ) was used for quantification. Measurements were performed in triplicate and results were expressed as \% CGA equivalent (eq.) (w/w). 


\section{Overall antioxidant capacity}

Direct $\mathrm{ABTS}^{+}$assay or QUENCHER assay, was carried out according to Açar, Gökmen, Pellegrini, and Fogliano (2009). Ten $\mathrm{mg}$ raw SCG were mixed with $90 \mathrm{mg}$ cellulose and stirred, $10 \mathrm{mg}$ of the mixture were mixed together with $1.7 \mathrm{ml}$ of $\mathrm{ABTS}^{+}$solution in a thermomixer $\left(25^{\circ} \mathrm{C}, 2 \mathrm{~min}, 600 \mathrm{rpm}\right)$. After centrifugation, absorbance of the supernatant was measured in microplate. A CGA and Trolox calibration curve $(10-200 \mu \mathrm{g} / \mathrm{ml})$ was used. Measurements were performed in triplicate and results expressed as \% Trolox eq. (w/w) and \% CGA eq. (w/w).

Indirect $\mathrm{ABTS}^{+}$decolourisation assay, in terms of radical scavenging activity was employed as described by Oki, Nagai, Yoshinaga, Nishiba, and Suda (2006). Absorbance was measured in microplate. Aqueous solutions of CGA $(0.15-2.0 \mathrm{mmol} / \mathrm{l})$ were used for calibration. All measurements were performed in triplicate and results expressed as \% CGA eq. (w/w).

\section{Food safety}

Microbiological analyses

Count of (I) total aerobic microorganisms, (2) aerobic microorganisms forming endospores and (3) moulds and yeasts, was carried out. All assays were performed in sterile conditions and with previous solubilisation of SCG ( $10 \mathrm{~g})$ in BPW $(90 \mathrm{ml})$ by using a stomacher $(230 \mathrm{rpm}$, I min). Different conditions were set for each analysis: (I) pour plate method, PCA medium, incubation at $30^{\circ} \mathrm{C} 72 \mathrm{~h}$; (2) pour plate, BHI agar medium, pre-incubation $\left(80^{\circ} \mathrm{C}, 10 \mathrm{~min}\right)$ and incubation at $37^{\circ} \mathrm{C} 48 \mathrm{~h}$; and (3) spread method, SDA with chloramphenicol and incubation at $25^{\circ} \mathrm{C} I 20 \mathrm{~h}$. Results were expressed as colony forming units (CFU)/g.

Food processing contaminants

Content of acrylamide (ACR) was determined by liquid chromatography coupled with tandem mass spectrometry and quantified by isotopic dilution, based on the method of Mesías, Holgado, Márquez-Ruiz, and Morales (20I5). For quantification a curve calibration with standard ACR (I-100 $\mu \mathrm{g} / \mathrm{l})$ was constructed. The limit of the quantitation was set at $16 \mu \mathrm{g} / \mathrm{kg}$. The accuracy of the results were recently demonstrated for crispbread in an inter-laboratory comparison study launched by Food Analysis Performance Assessment Scheme (FAPAS) program (20I5), yielding a z-score of 0.3. Results $(n=4)$ were expressed as $\mu g$ ACR/kg dry weight. Hydroxymethylfurfural (HMF) was determined by liquid chromatography coupled with a diode array detector as described by Rufián-Henares, Delgado-Andrade, and Morales (2006). The limit of quantification was set at $0.6 \mathrm{mg} / \mathrm{kg}$. Analysis was performed in duplicate. Results were expressed as $\mathrm{mg} \mathrm{HMF} / \mathrm{kg} \mathrm{dry}$ weight.

Advanced glycation end products

Prior to analysis sample preparation was carried out as described in Section 2.5.9. Fluorescent and total AGEs were determined as follows: Fluorescence of AGEs was measured at $\lambda_{E x}=360 \pm 40 \mathrm{~nm}$ and $\lambda_{E M}=460$ $\pm 40 \mathrm{~nm}$ in a microplate fluorescence reader. Samples were analysed in triplicate. Results were expressed as fluorescence units $(\mathrm{FU}) / 100 \mathrm{~g}$ biscuit.

Competitive enzyme-linked immunosorbent assay (ELISA) kit was employed to determine total AGEs in the biscuit samples. The assay was performed according to the manufacturer's instructions. Results were expressed as total AGEs units $(\mathrm{U}) / 100 \mathrm{~g}$ biscuit.

\section{Sensorial quality}


Sensorial analysis of the innovative (BI, B2, B3, B4, B5, B6) and commercial $(\mathrm{Cl}, \mathrm{C} 2)$ biscuits was carried out applying a hedonic sensory test. Sensory evaluation was performed in different sessions involving in total 26 untrained panellists. Colour, texture, taste and overall acceptance of the selected biscuits were tested. Results of the verbal scale test were converted into a 7-point scale scoring I (lowest)-7(highest) and the average of the panellists' scores was calculated.

\section{Statistical analysis}

Statistical analyses were performed using SigmaPlot II.0 (Systat Software Inc., California, USA). Data were expressed as the mean value \pm standard deviation (SD). Analysis of variance (ANOVA) and the Fisher post hoc test were applied to determine differences between means. Differences were considered to be significant at $\mathrm{p}<0.05$.

\section{RESULTS AND DISCUSSION}

\section{Validation of SCG as food ingredient}

Physicochemical characterization

Data on physicochemical characterization are summarized in Table 2. Freeze-dried SCG presented 3.6\% moisture equivalent to aw value lower than 0.1. Growth of microorganisms and chemical degradative reactions might be widely decreased. The content in ashes $(0.5 \%)$, fat $(24.3 \%)$ and energetic value (4II $\mathrm{kcal} / \mathrm{l} 00 \mathrm{~g}$ ) is in concordance with those described by others authors regarding SCG from soluble coffee (Lago, Antoniassi, \& Freitas, 200I; Pujol et al., 20I3). As in coffee bean, carbohydrates are the main components present in SCG (Table 2). Polysaccharides, different to those quantified as dietary fibre, ranged $13.1 \%$, and free glucose content was nearly insignificant $(0.04 \mathrm{~g} / 100 \mathrm{~g} \mathrm{SCG})$ indicating low presence of glycaemic sugars. Results for total dietary fibre $(47.3 \mathrm{~g} / 100 \mathrm{SCG})$ are in line with those reported by Lago et al. (200I) and Vardon et al. (20I3). SCG dietary fibre is mainly composed of insoluble fibre ( $88 \%$ total dietary fibre), representing the $41.6 \%$ of spent coffee. SCG are rich in mannose, galactose, glucose and arabinose polymerized into hemicellulose and cellulose $(45.3-51.5 \%, \mathrm{w} / \mathrm{w})$ (Ballesteros, Teixeira, \& Mussatto, 2014; Mussatto, Carneiro, Silva, Roberto, \& Teixeira, 20II) and high presence of galactomannan (Simões, Nunes, Domingues, \& Coimbra, 2013). Lignin is also present in a significant amount in SCG $(19-26 \% \mathrm{w} / \mathrm{w})$ (Ballesteros et al., 2014; Pujol et al., 2013).

Caffeine and CGA are the major bioactive compounds of coffee. Freeze-dried SCG showed values of 200 $\mathrm{mg}$ caffeine/100 g and $10 \mathrm{mg}$ CGA/100 g SCG, respectively. CGA content ranged lower values than those described by others authors (Bravo et al., 20I2; Cruz et al., 20I2; Murthy \& Naidu, 20I2a; Mussatto et al., 20II; Panusa et al., 2013). These differences might be attributed to solvent extraction, set conditions, method of quantification, brewing method and origin of SCG. However, caffeine content perfectly fits in with those reported by Cruz et al. (20/2). Regarding the overall antioxidant capacity measured by ABTS method (Table 2), $0.33 \%$ CGA eq. (w/w) was found for SCG. The contribution of phenolic compounds to overall antioxidant capacity is shown in Table 2. The TPC of SCG ranged $0.18 \%$ CGA eq. (w/w) corresponding to the $50 \%$ of total antioxidant capacity. This result was in concordance with those reported by Pujol et al. (2013) for SCG aqueous extracts from soluble coffee.

As far as protein content is concerned, SCG showed significant amount of proteins (II.2\%, w/w). These values were inside the range reported by other authors, 6.7-9.9\% (Lago et al., 200I) and 12.8-16.9\% (Cruz et al., 2012). SCG protein content exceeds the amount presents in coffee bean due to the concentration of nonextracted components such proteins in coffee residues during instant coffee preparation. 
Data on amino acids (AAs) content were analysed (Table 3). The essential AAs comprise $42 \%$ of the total SCG amino acids which is smaller than the $49 \%$ described by Lago et al. (200I). Glutamic acid, threonine, aspartic acid and leucine presented the upper values, unlike data previously reported for SCG (glutamic acid, leucine, valine and isoleucine) (Lago et al., 200I). Fischer's ratio is the ratio of branched-chain AAs (BCAAs: leucine, valine, isoleucine) to aromatic AAs (AAA: phenylalanine, tyrosine) and play an important role, mainly, in liver diseases (Ishikawa, 20I2). As can be observed (Table 3) a value of 3.39 for the Fischer's was obtained which is higher than those described for SCG, coffee pulp and soymeal (Campos-Vega, Loarca-Piña, Vergara-Castañeda, \& Oomah, 2015). Proteins with high BCAA, Fischer's ratio and low AAAs are sought for functional foods field in order to support special requirements in malnourished patients associated to cancers, burns, trauma, and liver failure among others (Oomah, $200 \mathrm{I}$ and references therein).

\section{Thermal stabilization of SCG}

Influence of drying conditions $\left(40^{\circ} \mathrm{C}, 70^{\circ} \mathrm{C}, 100^{\circ} \mathrm{C}\right.$ and lyophilisation) on moisture loss (ML), moisture content (MC) and aw of SCG is presented in Table 4. Significant differences were not found between SCG70, SCG-100 and SCG-Ly ( $>>0.05)$ for ML (95.96-96.31\%) and MC (2.3-2.5l\%) ( $>$ > 0.05), However, SCG40 showed values significantly lower and higher $(p<0.05)$ for $M L$ and $M C$, respectively. Regarding aw parameter, the higher temperature the lower available water was observed $(0.35-0.05)$ and the minimum value was obtained by SCG-Ly, prolonging the shelf life of the product. In contrast, lyophilisation energy consumption (99.3 kW.h) was far superior to SCG-40, SCG-70 and SCG-100 (0.163, 0.177, 0.198 kW.h). Therefore, an adequate balance comprising product stability and moderate energy consumption might lead to select as the best drying conditions, $40^{\circ} \mathrm{C}$ and $70^{\circ} \mathrm{C}$.

\section{Food safety of SCG}

Results for raw SCG showed values below $102 \mathrm{CFU} / \mathrm{g}$ for endospores, $104 \mathrm{CFU} / \mathrm{g}$ of total aerobic microorganisms, content of yeasts lower than $107 \mathrm{CFU} / \mathrm{g}$ and absence of moulds. Regarding the thermal stabilized SCG, values below 10 CFU/g were found for all microorganisms under study. No microbiological regulations have been stablished for coffee. The principal hazard in terms of safety is the presence of ochratoxin A (OTA), a mycotoxin released by Aspergillus and related species with high incidence in coffee (Codex Alimentarius, 2009). OTA is potentially nephrotoxic, carcinogenic, teratogenic and possibly genotoxic. The Joint Expert Committee for Food Additives (JECFA) established a provisional tolerable weekly intake of $100 \mathrm{ng} / \mathrm{kg}$ of body weight and maximum permissible limits relative to 5 and $10 \mu \mathrm{gg} / \mathrm{kg}$ in roasted ground coffee and instant coffee, respectively (European Commission Regulation (EU) No 123/2005, 2005). The absence of moulds in SCG reduces the risk of OTA contamination. Thus, SCG presented excellent microbiological quality and thereby SCG becomes a safe food ingredient.

Regarding food processing contaminants, two neoformed contaminants have gained much interest, ACR and HMF. Both are considered as potentially carcinogenic to humans or precursors of potentially carcinogenic compounds. SCG presented $37.2 \pm 0.4 \mu \mathrm{g} \mathrm{ACR} / \mathrm{kg} \mathrm{d.m}$. which were less than those found in roasted coffee $(256 \mu \mathrm{g} / \mathrm{kg})$ and instant coffee (II $23 \mu \mathrm{g} / \mathrm{kg}$ ) based on 2010 monitoring data (EFSA, 20I2). Moreover, ACR values detected in our samples were $92-96 \%$ (SCG) lower than the indicative values proposed by European Commission (2013). Regarding the HMF, $61.3 \pm 0.4 \mathrm{mg} \mathrm{HMF} / \mathrm{kg} \mathrm{d.m}$. was found in SCG. Different authors reported HMF levels in coffee $(100-1900 \mathrm{mg} / \mathrm{kg})$ and instant coffee $(400-4100 \mathrm{mg} / \mathrm{kg})$ superior to our results (Capuano \& Fogliano, 20II and references therein). In this sense, SCG are small source of ACR and HMF.

Evaluation of SCG as dietary fibre 
Results relative to thermal resistance showed that insoluble fibre did not experiment change after submitting SCG at $185^{\circ} \mathrm{C}$ for $16 \mathrm{~min}$. SCG was also resistant to in vitro oral gastrointestinal digestion $(p>0.05)$. Moreover, soluble fraction of SCG digests exhibited low antioxidant capacity by ABTS and TPC relative to $46.14 \pm 3.61 \mathrm{mg}$ CGA eq./g digest $(0.06 \% \mathrm{w} / \mathrm{w} \mathrm{SCG})$ and $15.56 \pm 0.95 \mathrm{mg}$ CGA eq./g digest $(0.019 \%$, w/w SCG), respectively. These results indicate soluble fraction of SCG digest contribute in approximately $18 \%$ total antioxidant capacity of SCG and therefore the remaining insoluble fraction might still maintain most antioxidant capacity linked to the insoluble fibre which would be in concordance with data reported by Jiménez-Zamora, Pastoriza, and Rufián-Henares (2015).

In conclusion, it can be stated that SCG from instant coffee process are natural source of antioxidant insoluble fibre, essential AAs, with low glycaemic sugars, resistant to thermal food processing conditions and digestion process, and totally safe. Therefore, SCG could be incorporated as food ingredient in bakery products for human consumption.

\section{Food application of SCG}

Nutritional quality and safety of innovative biscuits

With regard to nutritional value, in terms of extractable protein content, the innovative biscuit containing SCG (4\%), stevia and oligofructose (B2) (19.47 $\pm 2.37 \mathrm{mg} / \mathrm{g}$ biscuit) did not present significant difference ( $\mathrm{p}>$ 0.05 ) with the commercial sucrose biscuit (CSB) (17.52 $\pm 1.44 \mathrm{mg} / \mathrm{g}$ biscuit). In contrast, amino acids content was significantly lower $(p<0.05)$ for CSB than for B2 biscuit, presenting values of $0.81 \pm 0.03$ and $1.03 \pm$ $0.01 \mathrm{mg}$ Lys eq./g biscuit ( $46.16 \pm 2.33$ and $53.3 \pm 6.6 \mathrm{mg}$ Lys eq./g protein), respectively.

Results concerning food safety showed values of $104 \mathrm{CFU} / \mathrm{g}$ for total aerobic microorganisms and endospores, and moulds and yeasts lower than $102 \mathrm{CFU} / \mathrm{g}$ for the innovative biscuit B2 and the biscuit elaborated using the same ingredients and recipe employed for preparing B2 without incorporation of SCG (control biscuit). These findings fit with those values stablished by the national microbiological standards for biscuits (RD I 124/82, 1982). The addition of SCG to the biscuit formulations did not increase the content of microorganisms suggesting the good microbiology quality of food ingredient.

Values of ACR and HMF in B2 were of $166 \pm 0.2 \mu \mathrm{g} / \mathrm{kg}$ and $8.3 \pm 0.1 \mathrm{mg} / \mathrm{kg}$, respectively. Values of $169 \pm 7.1$ $\mu \mathrm{g} A C R / \mathrm{kg}$ and $6.4 \pm 0.3 \mathrm{mg} \mathrm{HMF} / \mathrm{kg}$ were found in biscuit elaborated using the same ingredients as $B 2$ without addition of SCG (control biscuit). As can be observed, no significant differences $(P<0.05)$ in ACR values were detected between the two biscuits. Therefore, results seem to indicate SCG do not contribute to the formation of ACR during baking. B2 presented an ACR content of $67 \%$ lower than those indicative ACR values $(500 \mu \mathrm{g} / \mathrm{kg}$ biscuit) by the European Commission (2013) and within the range stablished for HMF in biscuits by the EFSA (2005) $(5 \mathrm{mg} / \mathrm{kg}-25 \mathrm{mg} / \mathrm{kg})$. As a consequence, the innovative biscuit can be considered safe for consumption.

On the other hand, CSB showed significant higher formation of Amadori compounds, in particular fructosamine $(621.28 \pm 30.9 \mu \mathrm{g}$ DMF eq./ $/ 00 \mathrm{~g}$ biscuit and $96 \pm 5 \mu \mathrm{g}$ DMF eq./mg protein) than B2 (498.04 \pm $4.9 \mu \mathrm{g}$ DMF eq./ $/ 00 \mathrm{~g}$ biscuit and $68 \pm 7 \mu \mathrm{g}$ DMF eq./mg protein), suggesting that faster evolution of the early stage of Maillard reaction occurred in the commercial sucrose biscuit. At this stage of the reaction, reducing sugars react with free amino groups to form Schiff base and then produce stable ketoamines (Culetu, Fernandez-Gomez, Ullate, del Castillo, \& Andlauer, 2016). The innovative biscuit (B2) does not contain reducing sugar to favour the formation of fructosamine unlike CSB. Negative consequence from Maillard reaction is the loss of nutritive value of proteins involved, with a loss of food quality. These 
Amadori products might reduce the bioavailability of essential amino acids such as lysine. Nevertheless, different studies have demonstrated the health-beneficial properties of Maillard reaction products (MRPs) (Tamanna \& Mahmood, 2015). Nowadays, the benefit/risk ratio of the Maillard reaction products in foods and health is a matter of great interest and controversy.

AGEs formation, in the advanced step of Maillard reaction, leads to a decrease of food safety (Poulsen et al., 2013). Fluorescent AGEs were formed in significantly higher amounts $(p<0.05)$ in CSB $(81.82 \pm 0.0 \mathrm{FU} / 100$ g) than in $B 2(60.78 \pm 2.15 \mathrm{FU} / \mathrm{l} 00 \mathrm{~g})$, which is related to the higher fructosamine content found in these biscuits. The content of total AGEs presented a similar behaviour. The content of total AGEs was 4-fold higher in CSB $(721.7 \pm 50.33 \mathrm{U} / \mathrm{l} 00 \mathrm{~g})$ indicating that the presence of sucrose in biscuits during baking increases the content, not only of initial MRPs, but also of the advanced ones. However, early MRPs often comprise the major proportion of the compounds formed (Poulsen et al., 2013). Comparisons among foods are difficult because of the multiplicity of methods and units with which AGEs are quantified. Nonetheless, it should be noted the feasibility of innovative biscuits and its ingredients when reducing the content of potentially harmful compounds. Sucrose replacement and SGC use entailed a decrease of all the MRPs measured. As explained, in absence of reducing sugars, Maillard reaction does not take place. Likewise, the content of CGA and other antioxidants present in coffee, and therefore in SGC, might also prevent this reaction (Fernandez-Gomez et al., 2015; Mesías et al., 2014). Hence, the innovative biscuits presented enhanced nutritional quality and safety.

Sensory analysis of biscuits

Colour, texture and taste were evaluated as presented in Table 5. All attributes were given a score higher than four. As regards colour, B2, B4 and B6 biscuits received the highest points, with similar scoring B6 and $C 2$ commercial biscuit $(P>0.05)$. Results relative to texture and taste showed that commercial biscuits and $B 2$ and B4 innovative biscuits did not present significant differences $(p>0.05)$.

Previous studies reported a decrease in the score for colour, texture and taste when stevia content increased. However, replacement of $20 \%$ sugar by stevia scored the highest values for these attributes (Kulthe, Pawar, Kotecha, Chavan, \& Bansode, 2014) and 100\% stevia in biscuits showed the maximum score for texture (Vatankhah, Garavand, Elhamirad, \& Yaghbani, 2015). The use of poly-alcohols as sweeteners in biscuits was also evaluated by sensorial analysis (Zoulias, Piknis, \& Oreopoulou, 2000) and maltitol presented the best score for flavour attribute. Our results are in line with these data.

For overall acceptance, as can be observed in Fig. I, those innovative biscuits containing SCG, oligofructose and stevia or stevia and maltitiol, or maltitol (B2, B4 and B6, respectively) in their formulation were scored significantly higher $(p<0.05)$ than their respective biscuits without oligofructose $(B I, B 3, B 5)$.

Caffeine from coffee and steviol glycosides from stevia exert long-lasting bitter after-taste in mouth (Hellfritsch, Brockhoff, Stähler, Meyerhof, \& Hofmann, 2012) producing occasionally undesirable effects in food matrix. Bitter aftertaste of stevioside is very persistent and appears in a dose dependent manner limiting its use at high concentrations.

Oligofructose presents slightly sweetness and therefore might act as enhancer of the taste in the innovative biscuits, masking negative off-flavours from stevia and SCG. Incorporation of oligofructose in biscuits also contributes to the balance of soluble: insoluble dietary fibre and promotes the growth of specific beneficial gut bacteria (prebiotic). Recently, relationship between non-digestible carbohydrates, including oligofructose, 
and reduction of post-prandial glycaemic responses was stablished by EFSA (2014). In this sense, oligofructose becomes a fundamental ingredient of these biscuits formulations.

Regarding, the overall acceptability of the innovative biscuits on the market (Fig. I), a comparison with commercial biscuits was performed. Biscuits containing oligofructose (B2, B4 and B6) did not show significant differences $(p>0.05)$ with those commercial biscuits $(\mathrm{Cl}$ and $\mathrm{C} 2$ ) presenting high consumer adhesion and similar characteristics to the innovative biscuits, in terms of incorporated hypocaloric sweeteners and dietary fibre content. The commercial (C2) and the novel biscuits (B2, B4 and B6) might be included inside the "high fibre content" nutritional claim approved by the European Commission Regulation (EU) No 1924/2006, according to estimated dietary fibre values (Table I).

Therefore, we could consider SCG and stevia and/or maltitol highly-accepted ingredients to include in innovative biscuits, and above all when combined with oligofructose in the formulation. Solid finished products were obtained according with consumers' preferences.

\section{CONCLUSION}

SCG from the industrial instant coffee are natural source of antioxidant insoluble dietary fibre, proteins, essential amino acids and low glycaemic sugars. SCG $(4 \% \mathrm{w} / \mathrm{w})$ can be used directly as food ingredient in solid foods such as biscuits without affecting the conventional food preparation and the final quality of the product. These food formulations might be destined to people with reduced energetic intake and particular requirements. The application of SCG which we propose represents a value-added opportunity for coffee by-products utilization at a very low cost.

\section{ACKNOWLEDGEMENTS}

This study was funded by SUSCOFFEE (AGL2014-57239-R) project. The present research is part of the PhD. Thesis of Martinez-Saez, N. FPI-predoc fellow belongs to Autonomous University of Madrid (UAM), Spain. Rebollo-Hernanz, M. thanks the JAE Intro fellowship (JAEINT_15_00086) and the FPU predoctoral program of the Ministry of Education, Culture and Sports (FPUI5/04238). Authors also thank Prosol for the spent coffee grounds and BENEO-ORAFTI for the FOS.

\section{APPENDIX A. SUPPLEMENTARY DATA}

Supplementary data associated with this article can be found, in the online version, at http://dx.doi.org/10.1016/j.foodchem.2016.07.173.

\section{REFERENCES}

Açar, Ö. Ç., Gökmen, V., Pellegrini, N., \& Fogliano, V. (2009). Direct evaluation of the total antioxidant capacity of raw and roasted pulses, nuts and seeds. European Food Research and Technology, 229(6), 96I969. http://dx.doi.org//0.1007/s00217-009-1131-z.

Ballesteros, L. F., Teixeira, J. A., \& Mussatto, S. I. (20/4). Chemical, functional, and structural properties of spent coffee grounds and coffee silverskin. Food and Bioprocess Technology, 7(12), 3493-3503. http://dx.doi.org/10.1007/s I| 1947-014-1349-z.

Bravo, J., Juániz, I., Monente, C., Caemmerer, B., Kroh, L. W., De Peña, M. P., \& Cid, C. (2012). Evaluation of spent coffee obtained from the most common coffeemakers as a source of hydrophilic bioactive compounds. Journal of Agricultural and Food Chemistry, 60(5I), I2565-12573. http://dx.doi.org// 0.102I/jf3040594.

Campos-Vega, R., Loarca-Piña, G., Vergara-Castañeda, H. A., \& Oomah, B. D. (2015). Spent coffee grounds: A review on current research and future prospects. Trends in Food Science \& Technology, 45(I), 24-36. http://dx.doi.org//0.1016/j.tifs.2015.04.012. 
Capuano, E., \& Fogliano, V. (20II). Acrylamide and 5-hydroxymethylfurfural (HMF): A review on metabolism, toxicity, occurrence in food and mitigation strategies. LWT - Food Science and Technology, 44(4), 793-810. http://dx.doi.org/10.1016/j.lwt.2010.11.002.

Codex Alimentarius (2009). Code of Practice for the Prevention and Reduction of Ochratoxin A Contamination in Coffee. CAC/RCP 69-2009. FAO/WHO.

Contini, M., Baccelloni, S., Massantini, R., \& Anelli, G. (2008). Extraction of natural antioxidants from hazelnut (Corylus avellana L.) shell and skin wastes by long maceration at room temperature. Food Chemistry, I10(3), 659-669. http://dx.doi.org//0.1016/j.foodchem.2008.02.060.

Cruz, R., Cardoso, M. M., Fernandes, L., Oliveira, M., Mendes, E., Baptista, P., \& Casal, S. (2012). Espresso coffee residues: A valuable source of unextracted compounds. Journal of Agricultural and Food Chemistry, 60(32), 7777-7784. http://dx.doi.org//0.1021/jf3018854.

Culetu, A., Fernandez-Gomez, B., Ullate, M., del Castillo, M. D., \& Andlauer, W. (2016). Effect of theanine and polyphenols enriched fractions from decaffeinated tea dust on the formation of Maillard reaction products and sensory attributes of breads. Food Chemistry, 197, 14-23. http://dx.doi.org/10.1016/j.foodchem.2015.10.097.

Del Castillo, M. D., Ames, J. M., \& Gordon, M. H. (2002). Effect of roasting on the antioxidant activity of coffee brews. Journal of Agricultural and Food Chemistry, 50(13), 3698-3703. http://dx.doi.org//0.1021/jf011702q.

Del Castillo, M. D., Martinez-Saez, N., \& Ullate, M. (2014). Healthy bakery products with high level of dietary antioxidant fibre. PCT/ES20 I4/070062. Spain.

Del Castillo, M. D., Fernandez-Gomez, B., Martinez-Saez, N., Iriondo, A., \& Mesa, M. D. (in press). Coffee by-products. In Coffee: chemistry, quality and health implications. Retrieved from <https://books.google.es/books/about/Coffee.html?id=LMk0jgEACAAJ\&pgis=1>.

Edwards, A. D., \& Slater, N. K. H. (2009). Protection of live bacteria from bile acid toxicity using bile acid adsorbing resins. Vaccine, 27(29), 3897-3903. http://dx.doi.org//0.1016/j.vaccine.2009.04.006.

EFSA (2005). Opinion of the Scientific Panel on Food Additives, Flavourings, Processing Aids and Materials in contact with Food (AFC) on a request from the Commission, Flavouring Group Evaluation 13 Furfuryl and furan derivatives with and without additional side-chain. EFSA Journal, (2I5).

EFSA (2012). Scientific Opinion. Update on acrylamide levels in food from monitoring years 2007 to 2010. EFSA Journal, 10(10), I-38. http://dx.doi.org/l0.2903/j.efsa.2011.2133.

EFSA (2014). Scientific Opinion on the substantiation of a health claim related to non-digestible carbohydrates and a reduction of post-prandial glycaemic responses pursuant to Article 13 (5) of Regulation (EC) No 1924/2006. EFSA Journal, I2(I), I-13. http://dx.doi.org/10.2903/j.efsa.2014.35I3.

Esfahani, A., Wong, J. M. W., Mirrahimi, A., Villa, C. R., \& Kendall, C. W. C. (201I). The application of the glycemic index and glycemic load in weight loss: A review of the clinical evidence. IUBMB Life, 63(I), 7-I3. http://dx.doi.org/10.1002/iub.418.

European Commission (2013). European Commission (EC) Recommendation of 8 November 2013 on investigations into the levels of acrylamide in food. Official Journal of the European Union, L 30I/I5. http://dx.doi.org/10.2903/j.efsa.2012.2938.

European Commission Regulation (EU) No 123/2005 (2005). European Commission Regulation (EC) No I23/2005 of 26 January 2005 amending Regulation (EC) No 466/200I as regards ochratoxin A. Official Journal of the European Union, L 25/3. Retrieved from file:///H:/TESIS/PAPER CARACTERIZ y APLICACI\%C3\%93N MARROS/PAPERS OTA/European Regulation OTA 2005.pdf.

European Commission Regulation (EU) No 1924/2006 (2006). Regulation (EC) No 1924/2006 Of the European Parliament and of the Council of 20 December 2006 on Nutrition and Health Claims made on Foods. Official Journal of the European Union, L404/9. 
Fernandez-Gomez, B., Ullate, M., Picariello, G., Ferranti, P., Mesa, M. D., \& del Castillo, M. D. (20I5). New knowledge on the antiglycoxidative mechanism of chlorogenic acid. Food \& Function, 6(6), 208I-2090. http://dx.doi.org/10.1039/C5FO00194C.

Garcia-Serna, E., Martinez-Saez, N., Mesias, M., Morales, F. J., \& Del Castillo, M. D. (20I4). Use of coffee silverskin and stevia to improve the formulation of biscuits. Polish Journal of Food and Nutrition Sciences, 64(4), 243-25I. http://dx.doi.org//0.2478/pifns-2013-0024.

Hellfritsch, C., Brockhoff, A., Stähler, F., Meyerhof, W., \& Hofmann, T. (2012). Human psychometric and taste receptor responses to steviol glycosides. Journal of Agricultural and Food Chemistry, 60(27), 67826793. http://dx.doi.org//0.1021/jf301297n.

Hollebeeck, S., Borlon, F., Schneider, Y. J., Larondelle, Y., \& Rogez, H. (2013). Development of a standardised human in vitro digestion protocol based on macronutrient digestion using response surface methodology. Food Chemistry, I38(2-3), 1936-1944. http://dx.doi.org/10.1016/j.foodchem.2012.11.041.

Ishikawa, T. (2012). Branched-chain amino acids to tyrosine ratio value as a potential prognostic factor for hepatocellular carcinoma. World Journal of Gastroenterology, 18(17), 2005-2008. http://dx.doi.org//0.3748/wjg.v18.il7.2005.

Jiménez-Zamora, A., Pastoriza, S., \& Rufián-Henares, J. A. (2015). Revalorization of coffee by-products. Prebiotic, antimicrobial and antioxidant properties. LWT - Food Science and Technology, 6I(I), 12-18. http://dx.doi.org/10.1016/j.Iwt.2014.11.031.

Kulthe, A. A., Pawar, V. D., Kotecha, P. M., Chavan, U. D., \& Bansode, V. V. (2014). Development of high protein and low calorie cookies. Journal of Food Science and Technology, 5I(I), 153-157. http://dx.doi.org/10.1007/s 13197-011-0465-2

Lago, R., Antoniassi, R., \& Freitas, D. D. G. C. (200I). Centesimal composition and amino acids of raw, roasted and spent ground of soluble coffee. Retrieved November 23, 2015, from <http://www.sapc.embrapa.br/arquivos/consorcio/spcb_anais/simposio2/industria09.pdf>.

Mesías, M., Navarro, M., Martínez-Saez, N., Ullate, M., del Castillo, M. D., \& Morales, F. J. (20/4). Antiglycative and carbonyl trapping properties of the water soluble fraction of coffee silverskin. Food Research International, 62, I I20-I I26. http://dx.doi.org//0.1016/j.foodres.2014.05.058.

Michalska, A., Amigo-Benavent, M., Zielinski, H., \& del Castillo, M. D. (2008). Effect of bread making on formation of Maillard reaction products contributing to the overall antioxidant activity of rye bread. Journal of Cereal Science, 48(I), 123-132. http://dx.doi.org//0.1016/j.jcs.2007.08.012.

Murthy, P. S., \& Naidu, M. M. (20I2a). Recovery of phenolic antioxidants and functional compounds from coffee industry by-products. Food and Bioprocess Technology, 5(3), 897-903. http://dx.doi.org//0.1007/s II947-010-0363-z.

Murthy, P. S., \& Naidu, M. M. (2012b). Sustainable management of coffee industry by-products and value addition - A review. Resources, Conservation and Recycling, 66, 45-58. http://dx.doi.org//0.1016/j.resconrec.2012.06.005.

Mussatto, S. I., Carneiro, L. M., Silva, J. P. A., Roberto, I. C., \& Teixeira, J. A. (201I). A study on chemical constituents and sugars extraction from spent coffee grounds. Carbohydrate Polymers, 83(2), 368-374. http://dx.doi.org/10.1016/j.carbpol.2010.07.063.

Mussatto, S. I., Machado, E. M. S., Martins, S., \& Teixeira, J. A. (201I). Production, composition, and application of coffee and its industrial residues. Food and Bioprocess Technology, 4(5), 66I-672. http://dx.doi.org/|0.1007/s|1947-01|-0565-z.

Oki, T., Nagai, S., Yoshinaga, M., Nishiba, Y., \& Suda, I. (2006). Contribution of b-carotene to radical scavenging capacity varies among orange-fleshed sweet potato cultivars. Food Sci. Technol. Res., 12, 156160. 
Oomah, B. D. (200I). Flaxseed as a functional food source. Journal of the Science of Food and Agriculture, 8I(9), 889-894. http://dx.doi.org//0.1002/jsfa.898.

Panusa, A., Zuorro, A., Lavecchia, R., Marrosu, G., Petrucci, R., Farmaco, D., \& Castro, V. (2013). Recovery of natural antioxidants from spent coffee grounds. Journal of Agricultural and Food Chemistry, 6I(I7), $4162-4168$.

Poulsen, M. W., Hedegaard, R. V., Andersen, J. M., de Courten, B., Bügel, S., Nielsen, J., \& Dragsted, L. O. (20I3). Advanced glycation endproducts in food and their effects on health. Food and Chemical Toxicology, 60, 10-37. http://dx.doi.org/10.1016/j.fct.2013.06.052.

Pujol, D., Liu, C., Gominho, J., Olivella, M. À., Fiol, N., Villaescusa, I., \& Pereira, H. (20/3). The chemical composition of exhausted coffee waste. Industrial Crops and Products, 50, 423-429. http://dx.doi.org/10.1016/j.indcrop.2013.07.056.

RD II24/82. RD II24/I 982, de 30 de abril, por el que se aprueba la Reglamentación Técnico-Sanitaria para la Elaboración, Fabricación, Circulación y Comercio de Galletas (1982). Spain.

Rufián-Henares, J. A., Delgado-Andrade, C., \& Morales, F. J. (2006). Application of a fast high-performance liquid chromatography method for simultaneous determination of furanic compounds and glucosylisomaltol in breakfast cereals. Journal of AOAC International, 89(1), 161-165. Retrieved from $<$ http://www.ingentaconnect.com/content/aoac/jaoac/2006/00000089/0000000 l/art00022?token $=005 \mathrm{cle} 5 \mathrm{c5}$ c473553e870dd5c5f3b3b47465276702577702a4a452a3 I4f582a2f4876753375686f49bf99a8808dbb>.

Simões, J., Nunes, F. M., Domingues, M. R., \& Coimbra, M. A. (2013). Extractability and structure of spent coffee ground polysaccharides by roasting pretreatments. Carbohydrate Polymers, 97(I), 8I-89. http://dx.doi.org/10.1016/j.carbpol.2013.04.067.

Tamanna, N., \& Mahmood, N. (2015). Food processing and maillard reaction products: effect on human health and nutrition. International Journal of Food Science, 2015, I-6. http://dx.doi.org/10.1155/2015/526762.

Vardon, D. R., Moser, B. R., Zheng, W., Witkin, K., Evangelista, R. L., Strathmann, T. J., \& Sharma, B. K. (20I3). Complete utilization of spent coffee grounds to produce biodiesel, bio-oil, and biochar. ACS Sustainable Chemistry \& Engineering, I (I0), I286-1294. http://dx.doi.org/10.102I/sc400I45w.

Vatankhah, M., Garavand, F., Elhamirad, A., \& Yaghbani, M. (20I5). Influence of sugar replacement by stevioside on physicochemical and sensory properties of biscuit. Quality Assurance and Safety of Crops \& Foods, 7(3), 393-400. http://dx.doi.org//0.3920/QAS2014.0396.

Vlassopoulos, A., Lean, M. E. J., \& Combet, E. (2013). Role of oxidative stress in physiological albumin glycation: A neglected interaction. Free Radical Biology and Medicine, 60, 3/8-324. http://dx.doi.org/10.1016/j.freeradbiomed.2013.03.010.

Zoulias, E. I., Piknis, S., \& Oreopoulou, V. (2000). Effect of sugar replacement by polyols and acesulfame-K on properties of low-fat cookies. Journal of the Science of Food and Agriculture, 80, 2049-2056. http://doi.org//0.1002/1097-0010(2000II)80:14<2049::AID-JSFA735>3.0.CO;2-Q. 


\section{FIGURES AND TABLES}

Table I. Innovative biscuit formulations: BI-100\% stevia (ST) and spent coffee grounds (SCG); B2-100\% ST. oligofructose (OF) and SCG; B3- 30\% ST. 70\% maltitol (MT) and SCG; B4-30\% ST. 70\% MT. OF and SCG; B5-100\% MT and SCG; B6-100\% MT. OF and SCG.

\begin{tabular}{|c|c|c|c|c|c|c|}
\hline Ingredientes (g) & $\mathrm{BI}$ & B2 & B3 & B4 & B5 & B6 \\
\hline Wheat flour & 61.54 & 59.37 & 55.11 & 55.53 & 52.83 & 53.35 \\
\hline Water & 21.98 & 21.20 & 19.68 & $|8.2|$ & 18.87 & 17.49 \\
\hline Sunflower oil & 8.52 & 8.22 & 7.63 & 7.06 & 7.31 & 6.78 \\
\hline Baking powder & 0.60 & 0.58 & 0.54 & 0.50 & 0.52 & 0.48 \\
\hline Salt & 0.41 & 0.39 & 0.36 & 0.34 & 0.35 & 0.32 \\
\hline Soy lecithin & 0.36 & 0.35 & 0.32 & 0.30 & 0.31 & 0.29 \\
\hline MT & 0.00 & 0.00 & 11.81 & 10.83 & 16.04 & 14.87 \\
\hline ST & 2.20 & 2.12 & 0.60 & 0.56 & 0.00 & 0.00 \\
\hline OF & 0.00 & 3.53 & 0.00 & 3.03 & 0.00 & 2.91 \\
\hline SCG & 4.40 & 4.24 & 3.94 & 3.64 & 3.77 & 3.50 \\
\hline Total & 100 & 100 & 100 & 100 & 100 & 100 \\
\hline $\begin{array}{l}\text { Estimated calories } \\
\qquad(\text { kcal } / 100 \mathrm{~g} \text { biscuit })\end{array}$ & 407 & 390 & 346 & 335 & 325 & 316 \\
\hline $\begin{array}{l}\text { Estimated fibre content } \\
\qquad \text { ( } \mathrm{g} \text { fibre/ } 100 \mathrm{~g} \text { biscuit) }\end{array}$ & $3.6^{*}$ & $7.5^{\dagger}$ & $3.1^{*}$ & $6.4^{\dagger}$ & $3.0^{*}$ & $6.1^{\dagger}$ \\
\hline
\end{tabular}

*BI. B3 and B5 might be "source of fibre" ( $\geq 3 \mathrm{~g}$ fibre/ $100 \mathrm{~g}$ biscuit)

† B2. B4 and B6 might be "high fibre content" ( $\geq 6 \mathrm{~g}$ fibre/ $100 \mathrm{~g}$ biscuit) 
Table 2. Physico-chemical characterization of spent coffee grounds (SCG).

\begin{tabular}{|c|c|}
\hline Analysis & SCG \\
\hline $\begin{array}{l}\text { Moisture (\%) } \\
\text { Aw }\end{array}$ & $\begin{array}{l}3.60 \\
<0.10\end{array}$ \\
\hline Ashes (\%) & 0.50 \\
\hline Polysaccharides (\%) & 13.10 \\
\hline Free Glucose ${ }^{\dagger}(\mathrm{mg} / \mathrm{l} 00 \mathrm{~g})$ & 3.38 \\
\hline \multicolumn{2}{|l|}{ Dietary Fibre } \\
\hline TDF (\%) & 47.30 \\
\hline IDF (\%) & 41.63 \\
\hline SDF (\%) & 5.67 \\
\hline Total Protein (\%) & 11.20 \\
\hline Nitrogen (\%) & 1.79 \\
\hline Fat (\%) & 24.30 \\
\hline \multicolumn{2}{|l|}{ ABTS } \\
\hline \multicolumn{2}{|l|}{ Direct } \\
\hline$\%$ Trolox eq. $(w / w)$ & 0.17 \\
\hline$\%$ CGA eq. $(w / w)$ & 0.33 \\
\hline \multicolumn{2}{|l|}{ Indirect $^{\dagger}$} \\
\hline$\%$ CGA eq. (w/w) & 0.39 \\
\hline \multicolumn{2}{|l|}{$\mathrm{TPC}^{\dagger}$} \\
\hline$\%$ CGA eq. $(w / w)$ & 0.18 \\
\hline \multicolumn{2}{|l|}{$\mathrm{CGA}^{\dagger}$} \\
\hline$\% 3-C G A(w / w)$ & 0.01 \\
\hline \multicolumn{2}{|l|}{ Caffeine $^{\dagger}$} \\
\hline$\%$ caffeine $(w / w)$ & 0.20 \\
\hline $\mathrm{Kcal} / \mathrm{l} 00 \mathrm{~g}$ & 411 \\
\hline
\end{tabular}

$\dagger$ Analyses performed on aqueous SCG extracts.

Results are expressed as mean $(n=3)$. 
Table 3. Amino acids composition (\% protein) of spent coffee grounds (SCG).

\begin{tabular}{|c|c|}
\hline Amino acids & SCG (\% protein) \\
\hline Alanine (Ala) & $2.34 \pm 0.71$ \\
\hline Arginine $(\operatorname{Arg})^{\mathrm{a}}$ & $0.01 \pm 0.01$ \\
\hline Aspartic acid (Asp) & $5.10 \pm 0.71$ \\
\hline Cysteine (Cys) & $0.15 \pm 0.01$ \\
\hline Glutamic acid (Glu) & $4.13 \pm 0.56$ \\
\hline Glycine (Gly) & $2.68 \pm 0.17$ \\
\hline Histidine $(\mathrm{His})^{\mathrm{a}}$ & $0.39 \pm 0.08$ \\
\hline Isoleucine (Ileu) ${ }^{\mathrm{a}}$ & $0.94 \pm 0.13$ \\
\hline Leucine (Leu) ${ }^{\mathrm{a}}$ & $2.49 \pm 0.37$ \\
\hline Lysine (Lys) ${ }^{\mathrm{a}}$ & $0.59 \pm 0.10$ \\
\hline Methionine (Met) ${ }^{\mathrm{a}}$ & $0.26 \pm 0.03$ \\
\hline Phenylalanine (Phe) ${ }^{\mathrm{a}}$ & $1.18 \pm 0.22$ \\
\hline Proline (Pro) & $1.63 \pm 0.29$ \\
\hline Serine (Ser) & $0.57 \pm 0.10$ \\
\hline Threonine $(T h r)^{\mathrm{a}}$ & $4.71 \pm 1.01$ \\
\hline Tyrosine (Tyr) & $0.33 \pm 0.09$ \\
\hline Valine $(\text { Val })^{\mathrm{a}}$ & $1.69 \pm 0.14$ \\
\hline Essential AAs (\% total) & $42.0 \pm 1.2$ \\
\hline BCAA (Val+Leu+lle) & $5.12 \pm 0.6$ \\
\hline AAA (Phe+Tyr) & $|.5| \pm 0.3$ \\
\hline Fisher Ratio & $3.40 \pm 0.3$ \\
\hline
\end{tabular}

Results are expressed as mean \pm standard deviation $(n=3)$

${ }^{a}$ Essential amino acids 
Table 4. Physical characterization -moisture loss (ML) (\%), moisture content (MC) (\%) and water activity (aw)- of SCG stabilized at $40^{\circ}, 70^{\circ}, 100^{\circ} \mathrm{C}$ and lyophilized (SCG-40, SCG-70, SCG-100, SCG-Ly).

\begin{tabular}{cccc}
\hline & $M L(\%)$ & $M C(\%)$ & $\mathrm{a}_{\mathrm{w}}$ \\
\hline SCG-40 & $92.76 \pm 0.66^{\mathrm{a}}$ & $4.51 \pm 0.4 \mathrm{I}^{\mathrm{a}}$ & $0.350 \pm 0.02^{\mathrm{a}}$ \\
SCG-70 & $96.31 \pm 0.20^{\mathrm{b}}$ & $2.30 \pm 0.13^{\mathrm{b}}$ & $0.141 \pm 0.01^{\mathrm{b}}$ \\
SCG-100 & $95.97 \pm 1.16^{\mathrm{b}}$ & $2.51 \pm 0.72^{\mathrm{b}}$ & $0.114 \pm 0.01^{\mathrm{c}}$ \\
SCG-Ly & $95.96 \pm 1.16^{\mathrm{b}}$ & $2.52 \pm 0.72^{\mathrm{b}}$ & $<0.05^{\mathrm{d}}$ \\
\hline
\end{tabular}

Data are presented as mean \pm standard deviation $(n=3)$. Different letters indicate significant differences $(p<0.05)$ between the samples of the same column 
Table 5. Sensory evaluation (I to 7 scale) of different biscuit formulations: BI- 100\% Stevia (ST) and spent coffee grounds (SCG); B2- 100\% ST, oligofructose (OF) and SCG; B3- 30\% ST, 70\% Maltitol (MT) and SCG; B4- 30\% ST, 70\% MT, OF and SCG; B5- 100\% MT and SCG; B6- 100\% MT, OF and SCG; CI- MT and $4 \%$ fibre and C2- MT, Isomaltitol and 8\% fibre. BI, B3 and B5 are potentially "source of fibre" ( $\geq 3 \mathrm{~g}$ fibre/ $/ 00 \mathrm{~g}$ ) and B2, B4 and B6 with "high fibre content" ( $\geq 6$ g fibre/l00g).

\begin{tabular}{|c|c|c|c|c|c|c|c|c|}
\hline & \multicolumn{8}{|c|}{ Biscuit Formulations } \\
\hline & $\mathrm{Cl}$ & $\mathrm{C} 2$ & $\mathrm{BI}$ & B2 & B3 & B4 & B5 & B6 \\
\hline Colour & $6.5 \pm 0.64^{\mathrm{a}}$ & $6.3 \pm 0.78^{\mathrm{a}, \mathrm{e}}$ & $4.8 \pm 1.48^{b, d}$ & $5.5 \pm 1.14^{\mathrm{c}}$ & $4.4 \pm 1.06^{b}$ & $5.3 \pm 0.97^{c, d}$ & $4.5 \pm 1.21^{\mathrm{b}}$ & $5.7 \pm|.3|^{e, c}$ \\
\hline Texture & $6.4 \pm 0.66^{a, c}$ & $5.9 \pm 1.02^{\mathrm{a}}$ & $4.2 \pm 1.50^{b}$ & $5.1 \pm 1.26^{b, c, d}$ & $4.8 \pm 1.39^{b, d}$ & $5.7 \pm 1.05^{\mathrm{a}, \mathrm{d}}$ & $4.8 \pm 1.48^{b}$ & $5.3 \pm 1.46^{, d}$ \\
\hline Taste & $5.8 \pm 1.00^{\mathrm{a}, \mathrm{c}}$ & $5.9 \pm 1.24^{\mathrm{a}}$ & $4.7 \pm 1.29^{b}$ & $5.2 \pm 1.17^{b, c}$ & $4.9 \pm 1.23^{b, d}$ & $5.4 \pm 0.94^{\mathrm{a}, \mathrm{c}, \mathrm{d}}$ & $4.6 \pm 1.27^{b}$ & $5.1 \pm 1.45^{b, d}$ \\
\hline
\end{tabular}

Data are expressed as mean \pm standard deviation $(n=26)$. In each row, values with different superscript letters are significantly different $(p<0.05)$. 
Figure I. Spider-web diagram which shows mean scores $(n=26)$ of $I-7$ scale for overall acceptance of innovative sugar-free (BI-B6) and commercial $(\mathrm{Cl}$ and $\mathrm{C} 2)$ biscuits and their external appearance. Different letters denote significant differences $(\mathrm{P}<0.05)$. Formulations were as follows: $\mathrm{BI}-100 \%$ Stevia $(\mathrm{ST})$ and spent coffee grounds (SCG); B2 - 100\% ST, oligofructose (OF) and SCG; B3 - 30\% ST, 70\% Maltitol (MT) and SCG; B4 - 30\% ST, 70\% MT, OF and SCG; B5 - 100\% MT and SCG; B6 - MT 100\%, OF and SCG, CI MT and $4 \%$ fibre, and $C 2-M T$, Isomaltitol and $8 \%$ fibre-. BI, B3 and B5 are potentially "source of fibre" (P3 $\mathrm{g}$ fibre/l00 g) and B2, B4 and B6 with "high fibre content" (P6 g fibre/l00 g).

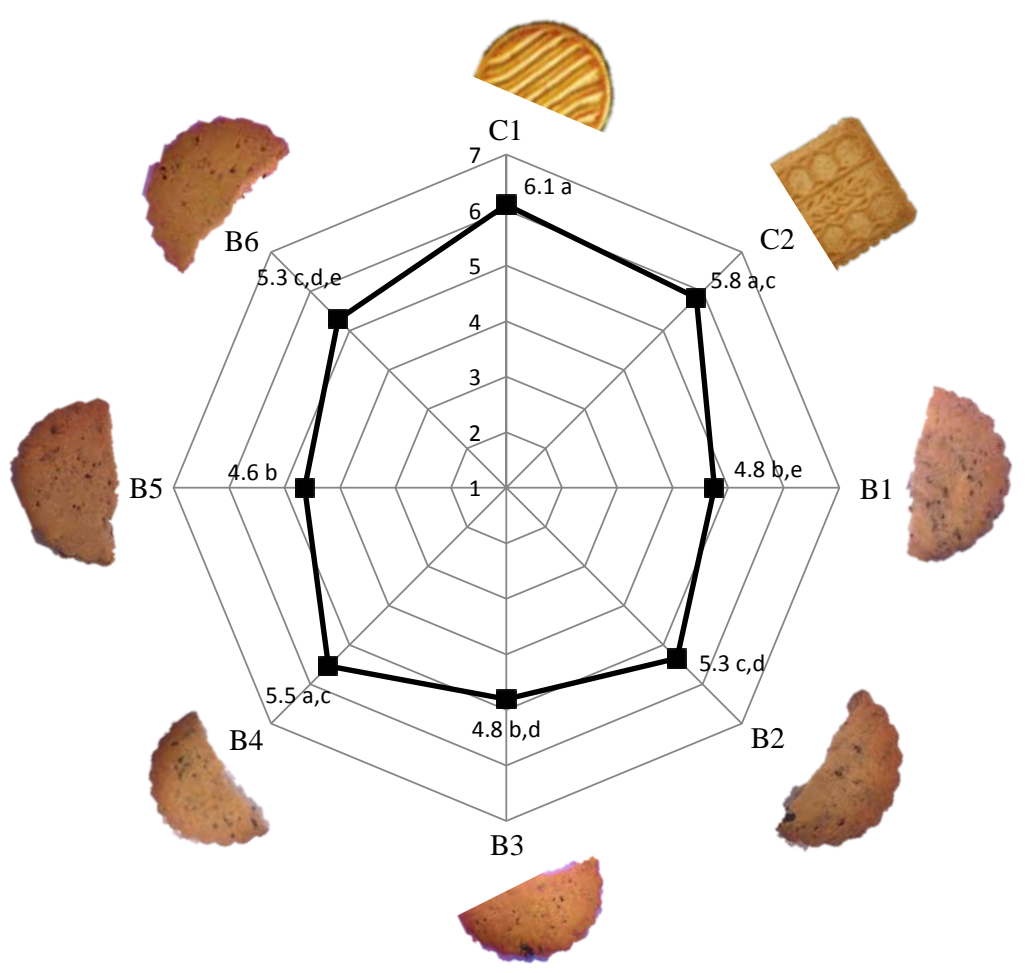




\section{Supplementary Material}

Table I. Nutritional composition of commercial biscuits: CI, C2 and CSB.

\begin{tabular}{lccc}
\hline & $\mathrm{Cl}$ & $\mathrm{C} 2$ & $\mathrm{CSB}$ \\
\hline Proteins & 6.4 & 6.1 & 6.5 \\
Carbohydrates & 67.9 & 64.9 & 67 \\
Sugars & $<0.5$ & $<0.5$ & 19 \\
Polyalcohols & 17.5 & 17.7 & - \\
Starch & 50.2 & 47.0 & - \\
Fat & 19.1 & 17.7 & 18 \\
Saturated & 1.9 & 1.8 & 5.8 \\
Monounsaturated & 14.9 & 13.8 & - \\
Polyunsaturated & 2.3 & 2.1 & - \\
Cholesterol & $<5$ & $<5$ & - \\
Dietary fibre & 3.6 & 8.3 & - \\
Sodium & 0.17 & 0.27 & 1 \\
Kcal & 450 & 432 & 470 \\
\hline
\end{tabular}

$\mathrm{Cl}$ : Wheat flour (62\%), sunflower oil (18\%), maltitol, isomaltitol, vegetal fibre, sodium and ammonium bicarbonate, salt, milk proteins, dextrose, vanilla aroma; C2: Whole wheat flour (56.5\%), sunflower oil (16.5\%), maltitol, vegetable fibre (4\%), pea fibre (3.7\%), sodium and ammonium bicarbonate, soy lecithin, salt, aroma; and CSB: Wheat flour, sunflower and palm oil, glucose and fructose syrup, whey powder, sodium and ammonium bicarbonate, salt, aroma, antioxidants, metabisulfite. 